\title{
Essential Communication Skills for Engineers, Scientists and Multi-disciplinary Teams
}

\author{
Samuel N. Cubero
}

\begin{abstract}
Most engineers and technicians are schooled in technical standards and analysis techniques to prevent material failure, malfunctions or performance problems, but many technical people are not formally schooled in 'effective communication standards' or 'good people skills' to prevent relationship failures and serious conflicts. Infighting, conflict, fear of speaking openly, tension, lack of respect and strained relationships are very common in many working environments, however, these problems are predictable, avoidable and solvable. This paper summarizes good values, attitudes and practical 'negotiation skills' that have been proven to be effective and even adopted as 'best practices' in other fields, such as business management, sales, politics and psychology. In order to avoid and resolve heated conflicts, people must be aware of common bad attitudes that need to be identified, corrected and avoided. Good 'people skills' can also be used effectively to overcome disagreements and conflicts between engineers and technical people, including students, who have little or no formal training in human psychology and basic principles of effective communication, negotiation and conflict resolution.
\end{abstract}

Index Terms-Communication, negotiation, psychology, teamwork, conflict resolution.

\section{INTRODUCTION}

In many western countries, the majority of new small businesses go bankrupt or shut down within the first ten years of operation. Approximately $60 \%$ of startup companies survive to age three and roughly $35 \%$ survive to age ten, according to the US Bureau of Labor Statistics [1]. Many factors can contribute towards the failure of a new business, such as poor productivity levels (often due to low motivation or poor worker morale), bad management decisions, poor organizational skills (bad information management and decision making), poor execution of projects and critical tasks, poor communication skills, in-fighting (bitter disagreements between managers) and the resignations or strike actions of highly-skilled workers whose needs were not satisfied.

According to a 'VitalSmarts' study [2] of more than 550 people, bad work assignments, unacceptable hours and low pay, are the least common reasons why people choose to resign. According to those surveyed, more than half said a disagreeable boss was their number-one reason to quit. The key results are as follows:

- More than $50 \%$ say a disagreeable boss is their number-one reason to resign.

Manuscript received March 13, 2016; revised July 13, 2016.

Samuel N. Cubero is with the Petroleum Institute, Abu Dhabi, UAE (e-mail: scubero@pi.ac.ae).
- $66 \%$ of people who are troubled by their boss are looking for other jobs.

- Almost $66 \%$ would resign without ever speaking their mind.

The popular saying: "People quit their bosses, not their jobs" [3], [4] succinctly explains one of the main reasons why people choose to resign. Highly productive, talented, valuable employees may choose to quit their jobs due to ongoing stress and dissatisfaction caused by their boss, or a coworker who repeatedly causes them stress and grief. Some of the reasons people resign include factors like higher paying job offers, wanting to relocate (e.g. to move closer to family and relatives), unresolved conflict, workplace bullying (constant criticism or harassment), lack of freedom to choose how one performs work, feeling unappreciated, boredom, lack of promotion opportunities, too much emotional stress and excessive workloads demanded by a 'bad boss' [5], [6].

Each of these problems can be discussed in great detail, however, this paper will focus on understanding common communication problems, defining 'values' and goals, bad attitudes displayed by 'difficult people' that typically lead to conflicts, and how to apply effective communication skills.

This paper describes practical strategies for resolving and avoiding conflicts. It highlights awareness of good and bad attitudes and values to notice (in yourself and in others) and describes essential attitudes and communication skills that promote good rapport, mutual purpose, mutual respect, high morale, motivation to work hard, accountability and peaceful relationships between workers - all of which are essential to achieve 'safe' honest communications and high productivity.

A big part of ethics is 'ethical behavior' or maintaining good rapport, collegiality, and a psychologically 'safe' working environment that encourages free, open and honest communications - one that is free from bullying, harassment and intimidation, and which encourages team participation, open discussion of all ideas, and even the challenging and analysis of all the pros and cons of all ideas, options and suggestions. It is also important for team members to know how to resolve or overcome initial disagreements without losing respect for each other (or without feeling defensive or getting angry), so that consensus, or a 'win-win' decision or outcome can be achieved that satisfies all team members. These are extremely important 'communication skills' used by successful teams that are not widely taught in schools or Universities, and are rarely taught by parents and friends. These skills can help people to avoid offending others, or avoid getting easily offended - while promoting the pursuit and discovery of the best possible solutions and decisions in a cooperative manner (without ego and self-interest as being 
the main motivator).

The old 'follow the leader' authoritarian style of management no longer works effectively in a 'knowledge-based' economy full of well-informed highly educated independent thinkers and creative people. Just like capitalism or a 'free market economy' is able to create abundant wealth, choices and career opportunities for many people, freedom of expression and 'safe dialogue' skills allow people to discover and consider many more ideas and options from a very large 'pool of knowledge', which could lead to discovering and implementing the best possible designs, solutions, ideas and decisions.

\section{Essential 'PeOPle Skills’ ARE nOt Widely KNOWN}

Many new projects are never completed and new businesses fail due to serious in-fighting and unresolved disputes within a team. Similar kinds of problems occur in many 'broken' families, leading to high divorce rates, separations and large numbers of 'run-aways' and homeless children. Unfortunately, many people simply do not know how to communicate in a manner that maintains or strengthens relationships with others. Many teams become unproductive and dysfunctional because one (or more) team member(s) experience serious ongoing problems that cause anger, frustration and emotional stress. Many people are also not aware of the most important communication skills and attitudes that are critical to achieve successful teamwork, conflict resolution and high performance.

The main problem with the 'image' of 'technical people', like engineers and scientists, is that they are often perceived as being socially awkward, or possessing low 'Emotional Intelligence' (or Emotional Quotient, EQ). Nerds, geeks, 'boffins' and highly-technical people (the kind depicted on 'The Big Bang Theory' sitcom or the 'Scorpion' TV show) have a reputation of being socially inept (often unsociable), awkward or poor at demonstrating good 'people skills'. While every individual is unique and different, 'technical people' often display common character traits. Many engineers and 'technical people' are assiduous, fastidious, detail-minded, competitive (often comparing themselves with others), highly judgmental (some are even critical or 'superior-minded'), and most are highly knowledgeable (in one or a few technical fields of science or engineering). 'Technical people' are usually concerned about matters regarding science, computers, tools, technology and 'gadgets'. They also seem to enjoy spending more time on their own (developing their careers, working on projects, and learning from books), rather than spending time with other people and developing relationships and good social skills. Many 'technical people' have not learned the basic principles of human psychology, conflict resolution and negotiation skills, from formal subjects, courses, textbooks or from interactions and communication with a wide variety of different people with different backgrounds. Some would rather focus on thinking only about themselves and their preferred way of doing things, without caring about the expectations, needs and feelings of other people. Some even disregard or fail to consider the desires, preferences and wishes of others, believing that other people's feelings and opinions are somehow intangible and unimportant. When one or more people in a team think like this, conflicts inevitably arise. This problem will be analyzed in detail later on.

In fact, most primary schools, high schools and Universities in western countries focus on teaching the mechanics and technicalities of speaking, reading, writing, computer software skills, mathematics and science. However, many public schools and Universities do not teach formal courses on effective communications, good morals, good ethics, success skills (good 'people skills'), 'Emotional Intelligence', building strong relationships and trust, effective negotiation and conflict-resolution (or conflict avoidance) - the most important skills needed for working well and communicating effectively with other people. Many schools and Universities do not teach such important topics neither do many popular forms of entertainment and media (TV shows, movies, video games, etc.) For most people, it seems that learning these important skills is left largely 'up to chance' whereby most people can only discover and develop such skills through 'incidental' life experiences, self-study, or informal ad-hoc guidance from a wise parent, mentor or adviser. Even many parents today are not aware of such important skills and, hence, children observe and tend to imitate many of the attitudes and behaviors of their parents, including their communication skills and 'people skills'.

Perhaps due to old traditions, schools promote the idea of 'being first', 'beating the competition' and 'being number one'. Many school teachers are not aware of good 'teamwork' attitudes and have little or no training in conflict resolution and negotiation skills. Hence, many teachers place great emphasis on individual achievement and students are encouraged to look superior, or appear smarter or more intelligent than others. Sports competitions, athletic events and debating contests promote the idea of 'winning the gold medal', dominating your opponent, and 'being the best'. Gold medals, Dux prizes and special awards are given to students who come 'first place', or 'top of their class', usually at a fancy prestigious public ceremony, in front of hundreds of adoring spectators and admirers. A self-centered competitive attitude (based on self-glorifying desires, such as 'I must dominate my competition', 'I must always come first place', or 'I must look superior to others') is not going to help a person gain the trust, respect and cooperation of coworkers or fellow team members in a workplace, who are often mistakenly viewed as 'competition' to be crushed and dominated [7], [8]. This is just one example of a 'bad attitude' that needs to be unlearned and avoided to maintain good rapport at work. More will be discussed in later sections.

\section{Why So Many COMmunication Problems?}

Occasionally, conflicts and bitter disagreements arise in the workplace and perplex even the most highly-qualified scientists, engineers, supervisors and managers (many of whom come from engineering or science backgrounds). Even highly educated 'technical people' may find themselves angry, bitter, 'stressed out' and thinking about resigning, because they are unable to solve serious human relationship 
problems and end serious conflicts with just the technical education they had gained as school students or undergraduate University students.

Because effective communication skills and good 'people skills' are not covered in typical primary and secondary school subjects, many young people naturally adopt values (virtues, vices, attitudes, beliefs, morals) and behaviors that they observe and accept from their family and friends, who, like them, may have adopted their values, attitudes and beliefs from various forms of entertainment media, like TV, films, news reports, documentaries, online movies, books, audio-books, video games, and online social networks.

Many of these forms of entertainment feature characters who demonstrate vices, bad values, unproductive character traits and bad communication skills (like yelling, arguing, fighting, threatening, pressuring, controlling, name-calling, insulting, slandering, showing violence, pretending, deceiving, masking, withdrawal, avoidance, ignoring, failing to listen, etc. to name just a few.) Many bad attitudes and bad behaviors learned from TV and movies are often treated by viewers as 'normal', acceptable and justifiable, based on the assumption that this is all just good 'entertainment' and harmless 'fun'. However, television shows, movies and video games provide 'vicarious experiences' that can and do influence the attitudes of people who are regularly exposed to and entertained by such vices [9]. Those who have deliberately chosen to practice good virtues and high moral standards are less susceptible to being influenced by fictional entertainment than inexperienced and highly impressionable young children and teenagers.

Choosing to sympathize with and be entertained by fictional characters (on TV or in movies) is not much different to choosing to associate with real life characters with similar attitudes and similar styles of communication. The attitudes and beliefs of those with whom you associate and even fictional characters that entertain you, will gradually be accepted and adopted by your 'conscious' or 'subconscious mind', even in a surreptitious and often imperceptible manner. These attitudes and beliefs can be 'good' or 'bad', 'positive' or 'negative', 'helpful' or 'harmful', 'worthwhile' or 'worthless'. Jim Rohn stated: 'You are the average of the 5 people you spend the most time with' [10] and this includes fictional characters.

Even fictional characters that you admire and consider to be respectable or decent 'role models' may demonstrate very poor communication skills, such as yelling in anger, arguing with a loud voice, and refusing to listen. To many viewers, these behaviors are acceptable and considered as 'normal'. Many people who become angry resort to 'silence' (hidden anger or withdrawal) or 'violence' (open attacking) thinking that their method of communication will get them the results they want (like cooperation, peace-of-mind, understanding, etc.), without realizing that they are only making things worse for themselves and for the other person. Hence, many people tend to (1) fight, compete with or try to dominate others, or (2) they completely avoid the other person who upset them, withdrawing from the source of stress, or (3) they stop all communications, completely 'freeze up', stay silent and avoid group participation and contributing further suggestions. Known as the 'fight, flight or freeze' responses
[11], these reactions are all symptoms of negative feelings like anger, resentment, fear and despondency (i.e. feeling helpless or powerless). When experiencing such negative emotions, most people will naturally feel aggressive, defensive or 'unsafe'. As a result of these negative emotions, they inevitably become unwilling to engage in further meaningful dialogue and may choose to avoid further communications.

Most of the bad communication skills that people practice today are based on what they have learned from watching thousands of hours of TV, movies, adventure video games, and from observing how their parents, family members and friends treat each other. Young children exposed to thousands of hours of TV entertainment encounter many different kinds of vices, bad attitudes and poor communication styles. Many children cannot distinguish the difference between fiction and reality, and many consciously or subconsciously accept, adopt and imitate such attitudes.

\section{Defining VAlues, InTENTIONS AND GoAls}

The first and perhaps the most important things for workers to know are the core values (ideals) and the 'mission statement' of a company (clearly stating the purpose, vision or main reason why the business or organization exists).

\section{A. Understand Core Values, Morals, Ethics and Attitudes}

Values include virtues, principles, ethics and good moral standards upon which a company should base all of its decisions, policies and code of conduct. These things should not be kept 'unknown' or 'left to chance'. For example, the following list can be used to remind all staff (especially management) to practice desirable 'values' and ideals. Here are a few suggested 'values' all staff and managers can pursue to maintain a productive and peaceful workplace:

1) Honesty, integrity, simplicity, accuracy, transparency, completeness, clarity, respect, helpfulness, effectiveness and speed are essential in all communications and work activities. All staff should strive to be helpful, caring, productive and goal-oriented in all their dealings.

2) All employees must produce value-adding work each working day, and complete all their essential duties;

3) Respect and consider all workers and their ideas / suggestions; Treat all with dignity, kindness \& fairness;

4) Strive for improved efficiency and performance in all areas of operation; (numbers/metrics can track progress)

5) Reward outstanding work that exceeds expectations;

6) Every worker should know and clearly explain all of his/her main areas of responsibility, or duties/tasks; (this should be checked by his/her manager or supervisor, both orally - or paraphrased - and/or in writing.)

7) Potential issues, predictable difficulties and problems should not be hidden, ignored nor tolerated (especially by management) but must be reported, discussed openly and fixed quickly, preferably by consensus; (including human behavior problems and any conflicts)

8) Maintain a peaceful, congenial, vibrant and productive work environment (correct or remove irritating bullies, trouble-makers or deliberately unproductive people);

9) Regularly examine and analyze work results, comments 
and/or feedback from people at all levels in the company, including those of clients and/or customers;

10) Keep learning and improving important and useful skills that are relevant to the mission of the organization; be open-minded and willing to consider implementing improvements and changes suggested by others.

11) Provide staff with adequate training to perform their duties competently. Organize and run skill-building courses to keep improving and upgrading staff skills.

12) Always be aware of the latest trends or technological advances in your industry or areas of expertise by attending the latest workshops and conferences. Strive to remain or become a leader in your field. Avoid complacency and keep searching for ways to improve.

The words of the 'mission statement' should ideally stir up strong feelings of commitment, purpose and pride among all workers in the company. This can be likened to a '50000 foot view' [12] from an airplane (the top-level 'big picture' or 'highest level goals' for a company). The 'mission statement' must be made clear to all managers and workers because it describes the main objectives and purpose for the organization's existence (and is the basis for all activities).

\section{B. Describe in Detail What Each Successful Goal Looks Like}

Before starting any major project or taking action on any goal, large or small, it is important to first visualize and clearly define (in writing) all the final results, deliverables or specific outcomes that you want to see achieved. Describe in detail 'what you want' (or all the specific conditions that must be achieved to regard a big goal or project as successfully completed). Also, describe in detail 'what you do not want' (or all the specific conditions or possible problems that you do not want to see which could lead to failure of the project). Identifying and understanding all the possible ways that a project can fail, and knowing the warning signs or indicators of poor outcomes, will help you to prepare detailed plans that can overcome, solve or prevent most foreseeable problems.

\section{Communicate Goals, Duties and Roles Clearly}

A manager, team leader or supervisor needs to explain objectives clearly and concisely to subordinates or team members. After a list of specific duties (or work tasks) is explained to a worker, the manager can check if the worker fully understands what is expected by asking the worker to repeat or paraphrase all instructions (either as oral or written feedback) [13]. This verification process will help to ensure that the worker fully understands all of his/her responsibilities and tasks, and will help to correct any misunderstandings or missed instructions. Asking the worker to write a short summary of agreed work duties is an even better way to check for full understanding, and this should be checked by the manager or team leader, especially before work begins. Communicating clear goals (with known schedules and deadlines acceptable to each worker) and allocating clearly defined work tasks will ensure that each worker knows what needs to be completed and by when (with start and end dates known, marked on a calendar or Gantt chart). Clarifying the roles and duties of each worker will also reduce confusion and inefficiency so that two or more workers do not end up performing the same task, and people do not waste time doing unimportant tasks [13]. Big projects often fail due to lack of awareness of potential problems, bad organization (poor information management and/or poor execution of essential tasks), incompetence (lack of necessary technical and problem-solving skills), and insufficient action.

\section{Good Communication Is Vital for Peaceful Relations}

Effective communication skills become increasingly important commensurate with the number of different people that a person must interact with on a daily basis. Typically, people are promoted based on their ability to successfully deal with and manage other people. Good 'people skills' is essential in management and supervisory positions. Bad outcomes, unhappy workers and project failures are usually caused or allowed to happen, mainly due to poor communication skills and poor 'people skills'.

Saying or doing something that appears insensitive, unkind or offensive to someone, and not knowing how to resolve conflicts or relationship problems, could lead to seriously bad consequences for those with low 'Emotional Intelligence' or poor 'people skills'. Poor communication skills can lead to ongoing petty nit-picking, in-fighting, internal competition driven by egotism, bullying behavior, sabotage, lack of cooperation and support, staff resignations, revenge attacks, negative and false performance reports based on personal grudges, the spreading of slander or false gossip, and even dishonest reports that can lead to a person getting fired, which can lead to serious revenge attacks, chronic depression, and sometimes even suicide. If these conflicts and relationship problems are not identified and corrected early enough, they can 'snowball' - grow out of control - and seriously destroy morale, motivation and productivity levels. Such problems and their solutions will be described in a later section.

\section{E. The 'Best Idea' Should Win}

It is important for all team members to be 'open-minded', willing to listen, and desirous of team cooperation and progress, rather than choosing to 'look superior' by fighting and arguing over 'preferred' ways of doing things or insisting on personal favorite methods or strategies (based on subjective opinions). When generating methods and strategies (options), they should always be considered as tentative choices [7]. Usually, there are many different methods or strategies that will work to accomplish a mutual goal or purpose. Of course, some will be better than others, but it is important for all to agree that 'the best idea should win', not the best debater, and not necessarily the person who has the highest rank (like the manager or team leader). Hence, it is important to discuss and analyze the 'advantages and disadvantages' of many different options or choices, and to strive for mutual agreement or 'group consensus' when important decisions are made, especially for decisions that affect many people. The best decisions are based on careful consideration of the largest number of available options (methods or strategies) for completing a goal or objective, and this can only be achieved by growing a large 'pool of knowledge' (a large collection of different ideas or options to 
consider) within the limited time available. Several minds are usually faster and better than one when brainstorming and generating new ideas, solutions, or options [8].

\section{BAD AtTitudes of 'Difficult People'}

Those with poor communication skills will try to compete with other team members and engage in heated arguments (somewhat like a 'battle of egos'), arguing that they have the better ideas or insisting that they came up with the best designs. Some even refuse to listen to other people's ideas. When you notice this, just accept their poor communication skills and do not try to change them nor chastise them in front of others (or you may cause more conflict and resentment by appearing to attack them or embarrass them - so avoid open confrontations). Those who raise their voices or try to pressure others into accepting their ideas will come across as egotistical 'know-it-alls', control-freaks [14], dictators and tyrants (i.e. self-centered, poor listeners who do not care about what other people think, and who imagine they are superior to and smarter than everyone else).

The following list describes some bad attitudes and irritating behaviors that should not be tolerated nor ignored, because often they lead to anger, frustration, poor communication, strained relations and uneasiness. These are some of the main causes for conflict, resentment, anger and avoidance in human relationships. These attitudes are noticeable in many human interactions and conversations. They often cause annoyance, lower productivity, lack of cooperation, and ongoing emotional misery or stress. They create an 'atmosphere' or environment that stifles open and honest communications - these attitudes destroy trust, respect, good rapport, and willingness to cooperate on big projects. This is not an exhaustive list, however, it describes several common attitudes of 'difficult people' who are not easy to work with, simply because such behavior can offend or create tension. A few of these are based on [8]:

1) Not admitting to your mistake, imagining you are perfect and incapable of making mistakes (perfectionism). Acting like a 'know it all', and refusing to learn from your mistake. Also, passing the blame to someone else not at fault, or trying to cover-up and conceal your mistakes. If you made a mistake, admit to it, apologize, and learn from it, rather than try to pass blame or try to hide it.

2) Being a hypocrite - failing to 'practice what you preach'; being incongruent (where words and actions do not match). Not caring enough to fulfill agreed expectations or promises, and accepting this as 'normal'. (Lack of integrity \& accountability) Most people will believe and trust physical actions much more than words!

3) Inability to respect others and forgive past mistakes; being overcritical or fault-finding (expecting perfection from others; or acting like a fastidious perfectionist.)

4) Comparing yourself to others, being competitive, jealous or envious (due to excessive feelings of self-importance, egotism and arrogance), which could lead to contempt.

5) Sabotaging other people's work, efforts or projects, or choosing to not cooperate and not help. Insecure people do not want others to look more successful or more talented - this problem is also known as the 'Tall Poppy
Syndrome' or 'Crab mentality'. 'Internal competitiveness' is a leading cause of conflicts, poor teamwork and lack of cooperation. When working with others in a team, it is far better to compete with and control yourself (to keep improving yourself), but do not compete with nor control others in your team.

6) Stealing or claiming all the glory and 'limelight' without acknowledging the contributions of others who helped; Failing to give or share credit or kudos where it is due.

7) Trying to make yourself look more important than others, boasting, showing off, failing to listen respectfully to others with an open mind; rudely interrupting or dominating the conversation by talking more than others; being pompous or showy, like an egotistical braggart. When others discover your good achievements, they will be far more impressed if you remain humble and demure and never boast about your achievements! Boasters appear to be glib, insecure and needy of other people's approval, admiration and attention. (Also called 'Toppers', or 'One-uppers')

8) Being a manipulative, coercive bully, control-freak or a dominating controller who tries to force or pressure people to accept his/her ideas, submit, agree or do something against their free will, using threats of punishment, intimidating body language (e.g. using stern or angry looks of disapproval), insults and frequent (sometimes false) disparaging or 'destructive' criticism. These people make the conversation 'unsafe', they discourage open and honest dialogue, and may insist that certain topics are closed or 'undiscussable' [7].

9) Belittling and disparaging other people or their achievements; trying to make another person look bad or stupid. Speaking aggressively or disrespectfully to make someone look inferior or unwelcome; spreading negative slander or false criticism, being persistently negative, nit-picking and critical (without any real supporting evidence). Looking for and emphasizing the worst traits (real or imagined); imagining the other person to be a 'villain' or inferior without any actual supporting proof. This may be due to a personal grudge, prejudice, jealousy or petty-minded 'internal competitiveness'. Spreading negative opinions, false stories or slander is intentionally done to destroy a person's reputation and make the accused person feel like a disrespected outcast. This can lead to distrust, hatred, opposition, avoidance and communication difficulties at work. Those who were attacked or slandered are usually afraid to confront and rebuke their attacker (to defend their reputation and expose the lies or false libel), so they often withdraw and avoid their attacker and those who concurred (even avoiding large groups of staff who did not question nor challenge the slanderer or accuser), hoping to avoid further attacks. Those who are habitually attacked usually isolate themselves and try to avoid their attacker and other staff members who did not challenge nor oppose the attacker. The person who chooses isolation may be hoping to avoid more attacks, but this only makes the situation worse, because others may start to believe that the negative gossip is all true, and that the accused is truly 
guilty and hiding in shame. Many people are willing to imagine and believe baseless gossip and slander from someone they trust as a familiar face or a friend, even if their words are false or misleading.

10) Believing and trusting in unverified stories (gossip, slander, unproven assumptions, subjective opinions, fake news) without first-hand observations or independent investigation and verification from several different sources. Such damaging information could simply be wrong, inaccurate, misleading (fabricated), false, baseless (lacking proof), or it could simply be based on biased 'cherry-picked' (subjective or carefully selected) evidence - usually negative or defamatory - that favors a particular personal opinion or the personal viewpoint of the attacker, slanderer or gossiper.

11) Expecting others to be your subservient slave and obey you. Expecting others to obsequiously serve you or treat you like an exalted leader, king, slave-master or 'someone special' who deserves unquestioned obedience. For bosses: being unreasonable and expecting workers to do things that you would not want to do, if you were in their position (overworking people, asking too much).

12) Unwillingness to take action to control or manage your own situation in life (relating to your career, finances, relationships, health, obesity, addictions, etc.). Being lazy, irresponsible and unwilling to 'pay the price' of good planning, learning and hard work (taking action) to achieve rewarding goals or results in the workplace and in life; finding excuses to procrastinate and avoid doing work. (Being indolent / lackadaisical / unproductive)

13) Imagining other people can 'read your mind' or 'understand what you want and what you don't want' without clearly communicating your expectations and without them agreeing to fulfill such expectations.

14) Constantly complaining and whining; imagining and looking for the 'worst' traits in other people, or in new ventures requiring some changes to existing procedures; nit-picking, complaining and choosing to focus mostly on negative things (even speculating or imagining the worst problems possible without any supporting evidence). These kinds of people feel a sense of control, comfort and importance when they tell listeners and sympathizers how unfair and difficult their life is, without realizing that they are making others feel miserable, depressed and demotivated (i.e. draining other people's energy). They can generate doubt, anxiety, negativity and fear of failure in other people (which can destroy potentially rewarding projects). These people are often called 'downers' and try to gain other people's attention by complaining or being negative and gloomy. They usually have low self-esteem and often imagine they are helpless or powerless victims.

15) Showing favoritism, negativity, prejudice or discrimination based on things that are outside of another person's control, like inherited DNA (race, skin color, facial features, ethnic background, height, or gender), nationality, etc.; e.g. Racism, male chauvinism. (Also known as over-generalizing, or stereo-typing)

16) Jumping to conclusions without carefully considering all the facts. Sometimes our imaginations can deceive us especially if we have a prejudiced view about someone. People will always 'find what they are looking for' - and some feel superior by being captious or caviling.

When a person habitually displays several of these 'bad attitudes' and knowingly or deliberately causes pain, irritation and misery for others, that person can be regarded as a 'difficult person', or a person who lacks empathy and care for others (i.e. a sociopath). The majority of people, on a 'bad day', may occasionally or inadvertently display one or more of these bad attitudes, but 'difficult people' display one or more of these 'bad attitudes' quite frequently or habitually.

\section{UnDERSTANDING 'DifFICUlt PEOPLE'}

This section identifies the personality traits of 'difficult people' and how to understand their mindset. All of the bad attitudes mentioned in the previous section are due to one or more personality problems or 'character flaws', namely:

- Egotism: An unnecessary desire to look, feel or act superior or more important than others (arrogance, self-glorification, excessive pride, hubris, petty vanity, also called narcissism); a common trait of control-freaks, perfectionists, highly competitive egomaniacs, boasters, bullies, racists, those who rudely interrupt you repeatedly before you finish speaking your sentence, and judgmental, overcritical, snarky, spiteful, nit-picking fault-finders who habitually criticize and belittle other people.

- Selfishness: Unwillingness to share, or desiring to steal or claim more than one's fair share of good things such as money, property, credit for good work, fame, control, even freedom; (greed / avarice, closely related to egotism); a common trait of obsessively materialistic or greedy people, control-freaks, sociopaths and criminals.

- Fear: insecurity, victim mentality, fear of failure, fear of the unknown, fear of exploring outside of one's comfort zone; a common trait of cowards, procrastinators and those who imagine they are helpless, powerless 'victims'.

- Negativity: pessimism, closely related to fear (e.g. fear of change, fear of failure, fear of looking ordinary or mediocre), and even egotism (e.g. desiring to look superior to another talented person); a common trait of habitual complainers, perfectionists, and gloomy, whining, cantankerous, grouchy people ('downers').

- Laziness: Indolence (apathy), irresponsibility, torpor; typical traits of hedonists and those who want to avoid hard work, studying, thinking, concentrating and/or physical labor, especially those with little motivation or no ambition to accomplish difficult and rewarding goals.

\section{A. Dealing with Difficult People}

These 'bad attitudes' should be highlighted and brought to the attention of 'difficult people' by discussing such issues with them in private, in order to avoid embarrassing them. 'Difficult people' need to know 'how' and 'why' such attitudes are incompatible with the values of the organization, and 'how' and 'why' their attitudes and past behavior caused problems, anger and conflict. Instead of appearing or sounding violent, upset, disappointed, angry, sarcastic, accusatory, judgmental and aggressive (which are indicators that you need to have a 'Crucial Conversation' [7]), replace 
these feelings with curiosity, inquisitiveness and wonder. The same is true when you start feeling like you want to 'withdraw' and 'avoid' another person who offended you. Most people first tend to remain 'silent' and avoid raising issues and concerns, hoping to 'keep the peace' and not offend the other person. However, long periods of sustained 'silence' regarding pressing issues and unresolved conflict eventually creates so much tension (like built up pressure inside a 'pressure cooker'), this often leads to a 'violent' verbal attack or an 'explosive' outburst of anger and abuse. Such an incident could be interpreted as an open attack on one's character, especially if that person is not fully aware of the problem. Resorting to 'silence' or 'violence' usually leads to growing anger and resentment and worsening relationships. Rather than remaining quiet and tolerant of 'bad behaviors', or giving in to rage and hatred, think and act like a scientist, detective or a crime scene investigator, not a judge. It is a mistake to make judgments without first thoroughly investigating and understanding all the relevant facts relating to an issue. Abandon all negative feelings and try to discover all the facts and events that led up to the feelings which caused what you believe to be 'bad behaviors'. The main goal is to understand all the facts and discuss these facts with the other person. The other person may actually have good reasons for his/her behavior, so do your best to understand such reasons.

Start off by meeting the other person in a private setting and calmly stating the facts or what you observed in an unbiased, objective, non-judgmental and tentative manner. Avoid making the other person feel defensive by keeping your volume low, never raising your voice in anger, and remaining relaxed and calm. Your goal should be to find out all the details of the other person's 'story' (or what he/she believes to be facts) and uncover factors that may have contributed to the 'bad behavior' so that you do not make the mistake of jumping to a wrong conclusion or make any wrong assumptions. For example, you could humbly say: "Please help me to understand something that has been bothering me... My intention is to find out what really happened and to solve this problem so it doesn't happen again, because I don't want anyone to suffer needlessly... all I want is an effective, long-term solution to this problem and I am hoping you can help me ... I could be wrong, but I am wondering why [state the facts or disappointing event or incident that happened]... I don't want to come across as critical, and please correct me if I am wrong, but can you please explain to me why this happened? ... [Listen carefully and avoid interrupting. To show you have been listening and paying attention, restate or paraphrase what the other person said. Calmly discuss and clarify your story and the other person's story, then ask this question respectfully:] ... What do you think are some possible solutions to this problem?" If the other person refuses to comment or still feels defensive or unsafe talking about this issue, calmly state what could be on his/her mind like this: "Are you worried about [mention a specific reason why he/she may be afraid to talk freely] ?", to indicate that it is 'safe' to openly discuss touchy, difficult or sensitive issues and problems. Make all 'undiscussable' topics 'discussable' and encourage open, honest dialogue, with a view to finding feasible and effective solutions to problems.

If the other person blames you for the problem or accuses you of wrongdoing, and shows evidence and undeniable proof, you should acknowledge your errors, humbly apologize, learn from your mistakes, give genuine thanks for the helpful feedback and discuss future corrective actions or methods of compensation. If the accusation is incorrect or you believe it is false or baseless, prove it by showing actual physical evidence or documents where possible, then ask the other person for physical evidence or actual proof to support his/her claims (just like in a real court of law). If the other person cannot produce any irrefutable proof or evidence of wrongdoing on your part, then calmly ask "What is the real reason behind your claims? Please help me to understand what is going on... What have I done to deserve your anger, contempt and disrespect? Have I offended you in some way?"

Try to get all hidden beliefs out into the open, for everyone to understand. Keep asking probing questions, like an unbiased crime-scene investigator or a detective, and avoid raising your voice. Avoid getting angry and emotional because feelings are a byproduct of beliefs and 'internal stories' in people's minds, including your own mind. Feelings and emotions are always based on 'stories' (i.e. thoughts, ideas and beliefs). Stories and beliefs need to be checked against hard evidence, facts and eyewitness accounts, because stories and beliefs could be true or false, accurate or inaccurate, complete or incomplete, based on accurate facts or based on imaginary fiction. Disrespectful angry words and accusations do not help to solve problems, nor do they make the conversation 'safe' for others to speak openly and truthfully. Your goal is to gather facts, reveal the 'truth', find out the complete story, listen to the other person's 'story' and beliefs, discover all the events and situations that led to the problem(s) and reveal your facts and your situation to the other person so that he/she can see every detail and can understand your experience from your 'point of view'. Once all the undeniable facts are revealed to all those involved, identify and openly discuss all bad behaviors and bad choices and compare them against the good values and morals that your organization is striving to pursue (Refer to Section IV). It is important for all people to understand the bad attitudes and situations that led to serious issues and conflicts in order to reduce the likelihood of them reoccurring in the future. Ensure that you are fully aware of your own attitudes and behaviors and check that your stories and beliefs are indeed accurate and complete, fully supported by undeniable facts, proof and strong physical evidence.

Where possible, avoid judging other people. Instead, let others judge their own actions and behaviors based on the facts that you present. When presenting such facts or evidence to support your statements, avoid 'rubbing it in' and overstating the mistakes of others in a manner that makes others feel miserable, worthless, stupid, discouraged or untrustworthy. Instead, present your facts like a teacher or a scientist, seeking to inform and educate with the intention of finding the best solution to the problem. Avoid looking 'smug' or self-righteous otherwise you will appear to be a 'judge and jury' or a barbaric, self-glorifying, domineering, competitive 'warrior' who just slaughtered all his enemies on 
a battlefield of war. People will naturally avoid you and secretly despise you if they feel intimidated by you or if they believe you do not respect them. Even if your facts are $100 \%$ true and you are 'in the right', always remain respectful, humble, discreet, calm and non-judgmental, in order to win other people's respect, support and future cooperation. Strive to achieve mutual agreement on a feasible solution to a particular problem or issue based on open honest dialogue.

'Difficult people' must be willing to accept and acknowledge their own attitude problem(s), decide to change, and strive to improve their attitudes and behaviors over time. It is very difficult or almost impossible to change the values, core beliefs, personalities and irritating behavior of other people without their willing consent and their appreciation and application of 'better ways' of thinking and behaving (i.e. good 'people skills'). It is best to avoid hiring a 'difficult person' who habitually displays 'bad attitudes' (especially if you notice bad attitudes in the job interview and during informal conversations) because his/her behavior will likely offend, discourage or demoralize others, and he/she will most likely create conflict and serious trouble in the future.

When you notice someone displaying one or more types of 'bad attitudes' or bad behaviors, it is important to question or challenge that person's statements or actions, and ask for facts or strong supporting evidence, especially if slander or criticism is spoken in front of a group of fellow workers. If the person displaying a 'bad attitude' cannot prove or justify his/her statements objectively, with actual facts, details or supporting observations from other eye witnesses, then talk to that person in private and explain why such attitudes are unproductive, harmful, or incompatible with the 'values' and mission of the organization.

If the 'difficult person' has a higher-rank in the organization than you, then discuss his/her bad attitudes and bad behaviors with someone who is higher-ranked than that difficult person, such as the boss of your boss, or your supervisor's supervisor. If the 'difficult person' happens to be your boss, supervisor, team leader or manager, you may feel very unsafe about speaking openly and honestly (because you may fear future retribution or punishment for correcting your boss - e.g. losing your job, losing his/her support and trust, increased workloads, poor performance reviews, etc.) If you believe you were treated unfairly, it is also highly likely that other staff members (of good repute) suffered similar problems over a long period of time. Bad attitudes always lead to bad behavior and conflicts. In this case, simply collect evidence of offensive and unprofessional behavior (such as printouts of insulting Emails, detailed descriptions of problems that were deliberately created by your boss, detailed factual accounts of serious problems that were deliberately ignored or covered-up, evidence of 'revenge attacks' and false slander, etc.) and ask other staff members to do the same if they feel the same way. After a sufficient amount of evidence has been collected by several staff members who experienced similar problems, organize to discuss the bad attitudes or bad behavior of your boss with higher levels of management. Several staff should meet with your boss' boss or even the company president in private. Also, request that the conversation remains completely confidential. Remaining relaxed, composed and professional when presenting your case is important for gaining the trust and respect of upper management. Once upper management understands how your 'difficult boss' has been habitually mistreating good workers, they may decide to replace or fire that 'difficult boss', or they will usually call for disciplinary action (e.g. perhaps reprimand the 'bad boss', demote $\mathrm{him} / \mathrm{her}$, or relocate the troublesome person to a different department where he/she cannot torture others). If this fails to create any real improvements, and if your boss still continues being a 'difficult person', you should consider resigning and looking for a new job. If you believe that the misery and emotional stress experienced in your job far outweighs all the monetary rewards and benefits, then resign after you receive a better job offer. All the money in the world cannot buy 'peace of mind' and restful sleep - things that cannot be achieved when a person is being bullied, constantly harassed, 'stressed out', overworked or tortured by a bully, or a 'difficult boss'.

\section{B. Understanding Control Freaks and Narcissists}

Domineering 'control-freaks' do exist in society and seem to be insecure when they are not in charge, or not in control of every decision. Control-freaks generally have little faith in the abilities and competence of others around them and they imagine that their 'superior knowledge' or 'superior intelligence' is absolutely necessary to achieve the best possible results. Some imagine that activities will go terribly wrong if they are not in control - micro-managing everyone's actions. They appear to relish the feeling of power when they are 'in charge' and 'calling all the shots'. Some sociopaths and control-freaks want to be seen in the 'limelight' as the 'glorified exalted leader' and commander, making all the final decisions and treating others like inferior servants or slaves. They usually do not respect 'freedom of choice' and will get offended if you disagree or challenge their peremptory edicts, ideas and opinions. In fact, some even take offence when you question them or try to offer possibly better alternative solutions or helpful suggestions. Unfortunately, these kinds of aggressive and dominating people are usually not aware of their own bad attitudes. Also, they are not aware of better styles of communication, management and decision-making. Looking superior and smarter is extremely important to them. Control-freaks assume that their ideas are automatically superior (because they imagine themselves to be smarter), hence, they are often poor at listening to and considering other people's views. They show little respect for other people below their 'rank' (or pay-grade) in a company and they find it very difficult to trust a person to make good decisions just because that person happens to disagree, or states a different or alternative viewpoint, suggestion or option. 'Control freaks' are usually stubborn competitive people who often behave like 'perfectionists' [15]. They often show signs of:

1) $O C P D$ - 'Obsessive-Compulsive Personality Disorder' [16] (feeling like they need to be in control of every single thing around them, including decisions and other people)

2) Narcissism [17] - imagining they are exemplary, brilliant, perfect, infallible, exalted, smarter, superlative and 'superior' in intelligence and/or physical attractiveness. 
3) Authoritarianism [18] - believing they should never be questioned, challenged nor disobeyed; choosing to severely restrict or limit the freedoms and choices of other people; and expecting others to behave like servile slaves.

Control freaks are very difficult to work with in a team because they typically believe 'My way is always best' or 'I am the smartest person in the room'. They will rarely accept correction, criticism or other people's advice, good ideas and suggestions (especially from others with a lower rank in the company). People with these kinds of bad attitudes can cause a great deal of unnecessary stress and misery, especially if they are in a position of power or influence. These kinds of people can be easily identified from 'formal complaints' and 'work satisfaction survey results' submitted by unhappy staff members. All 'difficult people' should be identified by higher-level managers and quickly replaced or removed from their positions of influence and authority to avoid causing further deterioration of staff morale and productivity. High-level management should not ignore the complaints and grievances of several staff who do not like their supervisor. The misery, revenge attacks, dirty-tricks, slander and emotional torture that trouble-makers inflict on others typically leads to depression, lower productivity levels, infighting, resignations and project failures. Self-respecting people do not want to feel constantly 'stressed out', angry, disrespected, insulted, belittled, ignored, treated like a mindless slave and repeatedly attacked or disadvantaged by a coworker they cannot influence, avoid or ignore (especially a sadistic, fault-finding, picky control-freak boss, or a bully).

If a 'difficult person' persists with harmful and damaging 'bad attitudes' (as described in the previous section) and shows no gradual improvement, even after being chastised, then stop associating with such a person, report that person's behavior to higher levels of management (using gathered facts and undeniable documented evidence collected over a long period of time), or take action to have that person removed from his/her position of influence or authority.

Narcissists usually behave selfishly and arrogantly, imagining that only their opinions, interests and goals matter. Some even desire to be the 'center of attention' and try to dominate team conversations by talking the most or talking the loudest, often rudely interrupting, being quick to criticize, refusing to discuss ideas that they disagree with, and failing to consider or listen to the ideas and suggestions of others. Sadly, self-centered 'closed-minded' people can make cooperation and collaboration very difficult, or sometimes, impossible, because they imagine only their views matter.

Bad attitudes are more contagious than good attitudes, and can seriously damage the morale and harmony in any workplace (or home), therefore, they must be corrected when they are first detected before they create serious conflicts, resentment and a total breakdown of open and productive communications. Brian Tracy suggests that we all ask ourselves: "What would this place be, if everyone is just like me?" [13] Don't forget to watch your own attitudes as well!

\section{GOOD ATTITUDES AND COMMUNICATION SKILLS}

Brian Tracy and Ron Arden, authors of the book "The
Power of Charm" [19], list five things that most people want and value in life (or the $5 \mathrm{~A}$ 's - which are mostly feelings!):

- Acceptance: feeling welcome, a sense of belonging

- Approval: being endorsed, recognized and honored

- Admiration: feeling respected, important and successful

- Appreciation: thanks, kudos or praise for good work

- Attention: being heard, noticed and considered

In addition, many people value other things like Autonomy (freedom to decide, self-sufficiency, or independence), Achievements (big challenging goals), Awards, Adventure (exploring remote places), Altruism (charitable activities), Awareness (learning and acquiring knowledge), Activity (athletics, sports), Action (games, action movies, sensory stimulation), Affluence (wealth), Attractiveness (beauty), etc.

In general, most human behavior follows this pattern:

- Values, morals and desires lead to thoughts.

- Thoughts lead to 'stories' (internal judgments, beliefs, and conclusions that could be right or wrong; accurate or inaccurate - they are based on 'what we are looking for')

- Stories lead to feelings (strong emotions)

- Feelings lead to actions, words, behaviors

- Actions lead to results and habits (good or bad)

- Results and habits lead to what you create in your life (good or bad), including your achievements and your legacy.

Stories determine how we interpret events and form conclusions about other people's intentions or agendas [7] so check that your story is accurate by comparing it to all the undeniable facts, and also check the other person's story.

\section{A. Summary of Good Attitudes}

Good attitudes are very simple to summarize:

- Base all decisions and actions on values and morals (see Section IV). Always remain respectful, kind and caring.

- Apply the 'Golden Rule': "Treat others the way you would like them to treat you"; and conversely: "Do not treat others the way you would not like them to treat you."

- Avoid all kinds of 'bad attitudes' (see Section V) by watching your own behavior and checking that your intentions and goals are always based on good values.

- Focus on being positive, avoid all forms of negativity, and continue to improve your life and the lives of others

- Build up other people's self-esteem (give the 5 A's above) and 'look for the best' in others (avoid being critical, unless a person is being unethical or unfair, breaking a law, causing real trouble or displaying a 'bad attitude').

- Be organized, goal-oriented, reliable and predictable in your own affairs and in your dealings with others. [12]

- Aim for consensus when making big decisions. Strive to keep all people you deal with as happy as possible by understanding and considering all their needs and goals.

\section{B. Persuasion - The Art of Influencing}

Before starting any negotiation, deal or discussion to finalize important decisions, it is important to agree on or define a 'common purpose' or 'expected outcomes' for the meeting [7]. Clearly define what each person wants, and what each person doesn't want. This requires careful listening and questioning, and giving up the idea of 'controlling' or 
'steering' the opinions of others. First establish a 'mutual purpose' by stating and writing down all the objectives or outcomes that each person wants to achieve. This forms the basis for subsequent talks. Write down important goals for all to see, openly discuss them and ensure that all people are satisfied and agree with the list of common objectives. Invite others to talk freely and express their ideas and opinions. Avoid being too strict, rigid and formal. Do not behave like a 'difficult person', dominating the meeting by insisting that everyone discusses only your talking points or only your ideas (because this will discourage others from participating). Encourage every team member to contribute their ideas and desires to grow the 'pool of knowledge' and don't act like the final decision maker. Disagreements and conflicts arise when people do not share 'mutual respect' and a 'common purpose' [7], or when goals or desires of others are not considered nor fulfilled. Such tensions and uneasiness can be avoided.

Whatever solution that you suggest or propose, always highlight the benefits for the other person, and focus on why it has the most advantages and the fewest disadvantages. Be prepared to compromise and meet most of the needs of the other person. Strive for a 'win-win' outcome so that every person gets 'most' of what they want, and no one leaves the deal 'empty-handed', feeling like a total loser.

Do not try to pressure others nor try to force others into 'agreeing' with you, or doing something against their will. Rather, help them see that what you want done is to their advantage and yours! Only other people can change their own attitudes, values, thoughts, opinions, feelings, habits and behavior. You may be able to influence or help other people to make changes or make good choices by appealing to their values and desires, and by showing them how certain choices or actions can be to their long-term advantage. Explain to others what you believe will be the positive and negative consequences, or the future advantages and disadvantages, of their choices. To sound more convincing, you need to provide strong proof or evidence to back up your claims, and present it in a respectful, relaxed and friendly manner, without appearing to be showy, pushy, smug or controlling. State your intentions openly by saying things like: "I am interested in finding the best possible solutions and outcomes for every person involved" and encourage every team member to comment freely, make suggestions and contribute their ideas. Other people want to be heard and have their opinions considered. It is possible to combine the ideas of several different people to create a feasible plan or strategy that everyone will support. The final plan or strategy does not have to be perfect, nor does it have to exactly match all of your preferences, however, it must satisfy most of the needs and objectives of people in your team (or all stakeholders).

Avoid trying to change other people's values, personalities or attitudes. This is virtually impossible to do, and only they can make such changes, not you. Once you know what other people really want (by listening well and understanding their needs), and after you plant 'seeds of suggestion' in their minds - showing them better ways of doing things, or beneficial reasons for change - other people will be able to understand the need for change and will want to change their attitudes and behaviors to benefit themselves. However, such change should appear to be advantageous to them and not just you alone. Lasting change in the thinking and attitudes of another person can only happen if that person decides to change or chooses to take action based on your suggestions.

\section{Criticism Does not Work - It Usually Offends}

Most people do not want to feel like they are being bullied, pressured, controlled or manipulated into doing things against their free will. Most people want the freedom to do things in the way that they believe 'is best' and most people will resent having their ideas ignored or ridiculed. If you disagree with someone, or if you believe your idea or decision is better, don't raise your voice and avoid arguing or debating with that other person. Avoid criticism, ridicule and sarcasm because these things can make other people feel like they are being attacked and disrespected. Raising your voice or criticizing others may be regarded as a form of 'controlling' or 'manipulation' using coercion. Criticizing or ridiculing a person's ideas in an aggressive manner is ineffective, disrespectful and offensive, and could make the other person feel angry or insulted. In fact, high-pressure debating and arguing tactics usually lead to distrust, resentment, defensiveness (heated arguments) or even withdrawal (avoidance) - negative emotional responses that could alienate or offend the other person, or destroy the other person's willingness to listen with an 'open mind'.

\section{Effective Negotiation - Just Offer Additional Choices}

Never use a hostile or combative tone of voice. Keep your volume low and non-threatening. Avoid intimidating body language, ridicule and personal insults, because this kind of approach will destroy trust and goodwill, and will only discourage others from making further contributions.

Rather, seek to inform, educate or provide the other person with additional 'options' to consider. Instead of criticizing or rubbishing another person's idea (which may be viewed as embarrassing or belittling), simply accept it as one option to consider, then suggest your proposal ('add' your idea to the existing (pool of knowledge') as a tentative option or alternative solution for the other person to consider. Let the other person see and judge the advantages and disadvantages of each additional option that you suggest so that he/she feels empowered and 'free to decide' or 'free to choose'. If the other person still does not like your ideas, then ask the other person to contribute his/her ideas or solutions, listen carefully without interrupting, and discuss all the advantages and disadvantages with an open mind. Remember to avoid controlling the conversation and always 'share' the talk time by not speaking more than other people. Listening more than you speak is courteous. The other person will most likely support solutions or decisions that are based on his/her own ideas and interests, and will usually want to take responsibility and work towards its success (to achieve a feeling of success).

Avoid becoming personally 'attached' or committed to a particular favorite idea, solution or strategy, even if you spent a long time developing it. Do not feel offended if people point out problems with your ideas or designs. When concerned people point out real problems with your idea and show credible proof, do not imagine this to be an attack on 
your character and do not take offense, rather, humbly and gratefully accept the constructive feedback and learn from it, so you can perhaps improve your idea or design. Such feedback may actually be constructive, crucial and beneficial and your ideas may indeed have disadvantages and some flaws that you did not consider. Keep an open mind at all times and welcome every team member's comments, ideas, feedback and contributions with a view to searching for the best possible idea or solution that satisfies all objectives and team members. Do not react like an oversensitive 'perfectionist' and do not assume that any negative comment about your idea or design is a disrespectful slur intended to belittle you or humiliate you. Caring people have good intentions, they want to be genuinely helpful and they also want to find and develop the best possible idea, design or solution. Do not allow your ego to 'blind you' or stop you from seeing and considering serious problems with your idea or design. Looking 'perfect' and 'flawless' in the eyes of others is not an important project objective, so avoid thinking like a 'perfectionist'. Mistakes, adjustments and corrections are to be expected in any kind of new project or venture, and are all part of the learning and improvement process.

\section{E. Remain Composed and Always Provide Supporting Facts}

All disagreements and differences of opinion can and should be resolved peacefully and calmly, using detailed analysis, facts and strong evidence (especially experimental evidence). Team harmony, cooperation and productivity usually suffer when (one or more) people assume dictatorial control and ignore the ideas, suggestions, preferences, needs and concerns of other team members. The 'best idea', or the 'best design' or solution is the one with the most advantages and the fewest (or no) disadvantages - the solution that best satisfies all the defined objectives or goals of the project [12], based on detailed analysis and evidence. The 'best idea' or the best option will become obvious to all team members by evaluating how well each idea or option achieves each of the project's objectives and how well all team members and stakeholders are satisfied with the final choices. Once everyone in a team is satisfied with the final decisions, discuss 'Who does what, and by when' and keep checking progress.

\section{CONCLUSIONS}

This paper described many important communication skills that are essential for building and maintaining peaceful, collegial and trusting relationships at work and even at home. Perhaps the most important points are:

- Apply 'good attitudes' and avoid all the 'bad attitudes'

- Give up the desire to dominate others. Avoid using power to control other people (unless you are high-ranking enough to discipline or remove willful troublemakers).

- Understand all objectives, goals and desired outcomes

- Find out what other people want and don't want

- Make decisions based on a large 'pool of knowledge'

- Aim for 'win-win' consensus-based outcomes or decisions: Listen well, ask many questions to understand what each person wants and what each person does not want, then agree on and pursue a common purpose.

- Avoid criticism - simply add new options to consider

- Examine the advantages and disadvantages for all options

- Listen more than you speak and avoid interrupting others

- Talk tentatively with a view to finding out all the facts

- Compare your story and other people's stories to the facts

- Present facts and strong evidence to support your beliefs, but do so respectfully and tentatively to win the other person's respect, trust and support, not win a debate.

- Keep an 'open mind' - remain adaptable and flexible!

- The 'best idea' should win, not the most dominating person

- Remain humble and modest; avoid acting superior to others (i.e. keep your ego and pride small and under control). Avoid thinking like an arrogant self-glorifying 'Narcissist', 'control-freak' or dictator who wants to look and feel 'superior' to others. These kinds of people are often irritating, offensive, unkind and selfish - typically very conceited, self-centered and lacking in empathy

- CARE: Consider, Assist, Respect and Encourage. Build up the knowledge, skills and self-esteem of others and always show consideration for the needs of others.

These are simple guidelines or 'rules of communication' that everyone on a team can follow, just like observing 'the rules of driving a car', or obeying 'road traffic rules'. If these basic rules of 'good communication' are observed and applied, most people will be able to feel respected and appreciated, and will have the motivation and ability to avoid and resolve most kinds of conflicts. If conversations are kept respectful, candid, 'safe' and focused on reaching consensus, relationships and commitments between people can remain stable, strong and enduring, while improving performance.

Communication is akin to playing a game or a sport like outdoor tennis. All players need to 'know the rules' and 'play by the rules', otherwise the game will no longer be enjoyable and fair, and players will end up fighting and arguing with each other over who is right and who is wrong. Your purpose should not be to dominate, humiliate or crush the other player, hog all the glory and become the 'center of attention'. Rather, a 'better purpose' would be to enjoy the game, have fun and see amazing performance and cooperation from everyone! Every person can choose his or her own purpose and 'values'.

Many projects, businesses and relationships have become disastrous failures due to the inability to learn and apply good communication skills and 'people skills'. Most human relationship problems are predictable and can be avoided or solved using the principles described in this paper. This author had studied more than 60 popular books on the market that deal with solving human relationship problems, conflict resolution, negotiation skills and 'people skills'. In the opinion of this author, the following books stand out as being the most beneficial and practical because they feature many detailed 'real world' demonstrations and examples to imitate:

- Crucial Conversations [7]

- Crucial Accountability [20]

- Influencer [9]

- The 5 essential people skills [21]

- Getting past No [22], [23]

These titles are also available as audiobooks (audio CDs). 
Google conducted a detailed survey on 180 of its teams [23] and found that 'Psychological Safety' was reported as one of the 5 most important traits of the most productive teams (i.e. ability to speak freely without fear or intimidation).

\section{REFERENCES}

[1] D. Gage. (2012). The venture capital secret: 3 out of 4 start-ups fail The Wall Street Journal. [Online]. Available: http://www.wsj.com/articles/SB100008723963904437202045780049 80476429190

[2] D. Gage, "The venture capital secret: 3 out of 4 start-ups fail," The Wall Street Journal, 2012.

[3] V. Smarts. Holding leaders accountable. Work for a Jerk? [Online]. Available: http://www.southamconsulting.net/resources/ or http://www.southamconsulting.net/resources/Holding\%20Leaders $\% 2$ 0Accountable\%20-\%20Summary\%20SC.pdf

[4] G. P. Smith. (2016). Top ten reasons why people quit their jobs. Business Know-How. [Online]. Available: http://www.businessknowhow.com/manage/whyquit.htm

[5] S. M. Heathfield. (2015). Top 10 reasons why employees quit their job. Human Resources About.com. [Online]. Available: http://humanresources.about.com/od/resigning-from-your-job/a/top-1 0-reasons-employees-quit-their-job.htm

[6] R. Luis, A. Domínguez, A. M. Marcelino, D. F. Cardona, and J. S. Fernández, "Why people leave their jobs?" International Journal of Business and Social Research, vol. 4, no. 11, pp. 71-83, 2014.

[7] T. Bradberry. (2016). 9 things that make good employees quit. Talentsmart. [Online]. Available: http://www.talentsmart.com/articles/9-Things-That-Make-Good-Empl oyees-Quit-172420765-p-1.html

[8] K. Patterson, J. Grenny, R. McMillan, and A. Switzler, Crucial Conversations - Tools for Talking When Stakes Are High, $2^{\text {nd }}$ ed, McGraw-Hill Education, 2011.

[9] J. C. Maxwell, The 17 Indisputable Laws of Teamwork: Embrace Them and Empower Your Team, Thomson Nelson, 2014.

[10] J. Grenny, K. Patterson, D. Maxfield, R. McMillan, and A. Switzler, Influencer: The New Science of Leading Change, 2nd ed., McGraw-Hill Education, 2013.

[11] Personal Excellence. You are the average of the 5 people you spend the most time with. Personal Excellence.co. [Online]. Available: http://personalexcellence.co/blog/average-of-5-people/

[12] Stress Stop. Fight, Flight or Freeze response to Stress. Stressstop.com. [Online].

Available: http://www.stressstop.com/stress-tips/articles/fight-flight-or-freeze-res ponse-to-stress.php
[13] D. Allen, Getting Things Done Fast: The Ultimate Stress-Free Productivity System, Nightengale Conant, 2001.

[14] B. Tracy, Full Engagement!: Inspire, Motivate, and Bring Out the Best in Your People, AMACOM, 2011

[15] Wikipedia. Control freak. Wikipedia.com. [Online]. Available: https://en.wikipedia.org/wiki/Control_freak

[16] Wikipedia. Perfectionism. Wikipedia.com. [Online]. Available: https://en.wikipedia.org/wiki/Perfectionism_(psychology)

[17] Wikipedia. OCPD (Obsessive-Compulsive Personality Disorder). Wikipedia.com. [Online]. Available: https://en.wikipedia.org/wiki/Obsessive\%E2\%80\%93compulsive_per sonality_disorder

[18] Wikipedia. Narcissism. Wikipedia.com. [Online]. Available: https://en.wikipedia.org/wiki/Narcissism

[19] Wikipedia. Authoritarian leadership style. Wikipedia.com. [Online] Available: https://en.wikipedia.org/wiki/Authoritarian_leadership_style

[20] B. Tracy and R. Arden, The Power of Charm: How to Win Anyone Over in Any Situation, AMACOM, 2006.

[21] K. Patterson, J. Grenny, R. McMillan, and A. Switzler, Crucial Accountability: Tools for Resolving Violated Expectations, Broken Commitments, and Bad Behavior, $2^{\text {nd }}$ ed. McGraw-Hill Education, 2013.

[22] Dale Carnegie Training, The 5 Essential People Skills: How to Assert Yourself, Listen to Others, and Resolve Conflicts, Touchstone, 2009.

[23] M. Schneider. Google Spent 2 Years Studying 180 Teams. The Mos Successful Ones Shared These 5 Traits. [Online]. Available: https://www.inc.com/michael-schneider/google-thought-they-knew-h ow-to-create-the-perfect.html?cid $=$ cp01002fastco

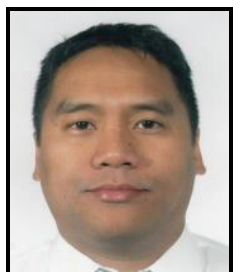

Samuel N. Cubero was born in 1972 and was raised and educated entirely in Australia since the age of 2 after his Filipino parents migrated from the Philippines in 1974. He completed his B.Eng (bachelor of engineering) degree, with honors, in 1993, at the University of Queensland, Brisbane, in mechanical engineering. He completed his $\mathrm{Ph} . \mathrm{D}$ in mechatronic (robotics) engineering at the University

of Southern Queensland (USQ) in 1998, specializing in embedded controllers, robotic walking vehicles, simulation programming and force, speed and position controlled actuators. From 1998 to 2010, he lectured and developed the teaching and lab materials for several new mechanical, mechatronics and robotics engineering subjects at Curtin University of Technology, Western Australia, and at USQ, Queensland. Currently, Dr. Cubero works as a full time academic at the Petroleum Institute, Abu Dhabi, United Arab Emirates (UAE). His CV and some sample videos of his work can be viewed at: www.samcubero.com. 